\title{
Correction to: Structural, thermal, and mechanical characteristics of yttrium lithium borate glasses and glass-ceramics
}

\author{
Kh. S. Shaaban ${ }^{1, *}$ (D), Ateyyah M. Al-Baradi ${ }^{2}$, Z. A. Alrowaili ${ }^{3}$, Atif Mossad Ali ${ }^{4,5}$, \\ M. S. Al-Buriahi ${ }^{6}$, and E. A. Abdel Wahab ${ }^{7}$ \\ ${ }^{1}$ Chemistry Department, Faculty of Science, Al-Azhar University, P.O. Box 71524, Assiut, Egypt \\ ${ }^{2}$ Department of Physics, College of Science, Taif University, P.O. Box 11099, Taif 21944, Saudi Arabia \\ ${ }^{3}$ Physics Department, College of Science, Jouf University, P.O. Box: 2014, Sakaka, Saudi Arabia \\ ${ }^{4}$ Physics Department, Faculty of Science, King Khalid University, Abha 61413, Saudi Arabia \\ ${ }^{5}$ Department of Physics, Faculty of Science, Assiut University, Assiut 71516, Egypt \\ ${ }^{6}$ Department of Physics, Sakarya University, Sakarya, Turkey \\ ${ }^{7}$ Physics Department, Faculty of Science, Al Azhar University, P.O. Box 71524, Assiut, Egypt
}

Published online:

29 October 2021

(C) Springer Science+Business

Media, LLC, part of Springer

Nature 2021

Correction to: Journal of Materials Science: Materials in Electronics (2021) https://doi.org/10.1007/s10854-021-07158-w

In the original version of this article, under Acknowledgements section, the Grant number relating to Deanship of Scientific Research at King Khalid
University, Saudi Arabia was incorrectly given as R.G.P.2/187/42, and should have been R.G.P.2/137/ 42.

The original article has been corrected.

Publisher's Note Springer Nature remains neutral with regard to jurisdictional claims in published maps and institutional affiliations.

The original article can be found online at https:/ / doi.org/10.1007/s10854-021-07158-w.

Address correspondence to E-mail: khamies1078@yahoo.com 